\title{
To invade or not to invade? Exploring the niche-based processes underlying the failure of a biological invasion using the invasive Chinese mitten crab
}

\author{
Zhixin Zhang $^{\mathrm{a}, *, 1}$, Stefano Mammola ${ }^{\mathrm{b}, 1}$, Colin L. McLay ${ }^{\mathrm{c}}$, César Capinha ${ }^{\mathrm{d}}$, Masashi Yokota ${ }^{\mathrm{a}, *}$ \\ a Graduate School of Marine Science and Technology, Tokyo University of Marine Science and Technology, Konan, Minato, Tokyo 108-8477, Japan \\ ${ }^{\mathrm{b}}$ Molecular Ecology Group (MEG), Water Research Institute, National Research Council of Italy (CNR-IRSA), Largo Tonolli 50, 28922 Verbania Pallanza, Italy \\ c School of Biological Sciences, University of Canterbury, Private Bag 4800, Christchurch, New Zealand \\ d Centro de Estudos Geográficos, Instituto de Geografia e Ordenamento do Território - IGOT, Universidade de Lisboa, Rua Branca Edmée Marques, 1600-276 Lisboa, Portugal
}

\section{H I G H L I G H T S}

- The failed establishment of invasive Eriocheir sinensis in Japan to date was studied.

- An n-dimensional hypervolume approach and species distribution models were used.

- Both methods suggested this species has undergone a niche shift during invasion.

- Model showed a mismatch between suitable freshwater and marine environments in Japan.

\section{A R T I C L E I N F O}

\section{Article history:}

Received 17 January 2020

Received in revised form 26 March 2020

Accepted 17 April 2020

Available online 20 April 2020

Editor: Sergi Sabater

\section{Keywords:}

Abiotic resistance

Biotic resistance

Catadromous species

Failed invasion

Habitat mismatch

Invasion risk

\section{G R A P H I C A L A B S T R A C T}

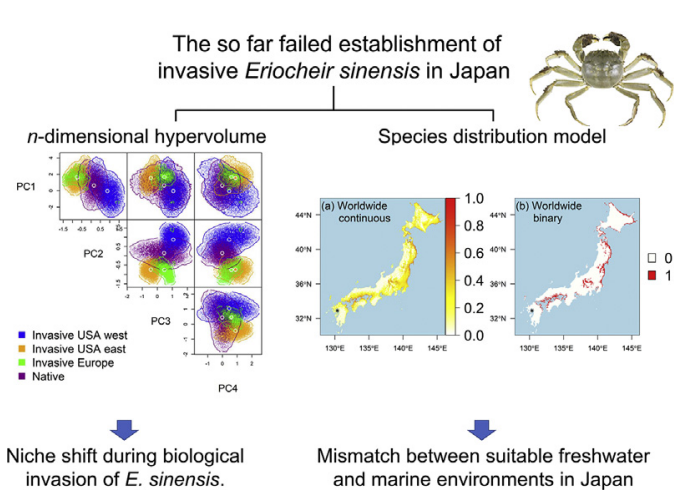

\begin{abstract}
A B S T R A C T
Invasive alien species represent a serious threat to global biodiversity, causing considerable damage to native ecosystems. To better assess invasion risks, it is essential to better understand the biological processes that determine the success or failure of invasions. The catadromous Chinese mitten crab Eriocheir sinensis, whose native distribution is the Pacific Coast of China and Korea, has successfully invaded and established populations in North America and Europe. In Japan, where E. sinensis is also regarded as potentially invasive and multiple introduction vectors exist, the species is not yet established. These settings can be used to explore niche-based processes underlying the apparent failure of a biological invasion. We first quantified native and invasive realized niches of $E$. sinensis in freshwater habitats using geometrical $n$-dimensional hypervolumes. Based on the assumption of niche conservatism, we then projected habitat suitability of this species in Japan using species distribution models (SDMs) calibrated with distinct sets of distribution data: native occurrences, invasive occurrences, and both. Results showed that $E$. sinensis has undergone either niche shifts or niche contractions during invasions in different areas of the world. Projections from SDMs indicate that although part of Japan is suitable for $E$. sinensis, this does not include the freshwater habitats around the Ariake Sea, which is considered to be a suitable marine environment for $E$. sinensis larvae. The mismatch between suitable freshwater and marine environments provides a
\end{abstract}

\footnotetext{
* Corresponding authors.

E-mail addresses: zhangzhixin1102@hotmail.com (Z. Zhang), yokota@kaiyodai.ac.jp (M. Yokota).

${ }^{1} \mathrm{ZZ}$ and SM contributed equally to this work.
} 
possible explanation for the failure of establishment of E. sinensis in Japan to date. Our findings have useful general implications for the interpretation of biological invasions.

(c) 2020 Elsevier B.V. All rights reserved.

\section{Introduction}

Biological invasions are regarded as a serious global environmental problem, with significant ecological, economic, and health-related consequences (Bellard et al., 2016; Ehrenfeld, 2010; Giakoumi et al., 2019; Morri et al., 2019; Pimentel et al., 2005; Simberloff et al., 2013). Numerous studies have shown that although complete eradication of established invasive species is possible, it is often expensive and prone to failure (Genovesi, 2005; Hänfling et al., 2011; Zhan et al., 2015). Therefore, it is highly recommended that effective control strategies for invasive species be implemented at the early stages of invasion (Giakoumi et al., 2019; Hänfling et al., 2011; Mehta et al., 2007; Zhan et al., 2015; Zhang et al., 2019a, 2019c). Many studies have documented successful biological invasions and the pathways of introduction typically involved (Jeschke and Heger, 2018; Lockwood et al., 2013). By contrast, comparatively little attention has been given to failed invasions (Allen and Ramcharan, 2001; Ings et al., 2010; Marchetti et al., 2004; Zenni and Nuñez, 2013). Studying successful invasions is of course the primary goal of invasion ecologists. However, researchers are increasingly recognizing the significance of failed invasions for advancing our general understanding of invasion ecology. This includes, for instance, the identification of the factors that determine invasion failure and which could be of use for supporting management actions and for improving invasion risk assessments (Allen and Ramcharan, 2001; Brockerhoff and McLay, 2011; Marchetti et al., 2004; Zenni and Nuñez, 2013).

Many factors have been suggested to drive the success or failure of biological invasions (Jeschke and Heger, 2018; Lockwood et al., 2013; Zenni and Nuñez, 2013). One of the most important factors concerns simply the availability of habitats that meet the physiological and life-history requirements of the species. A common expectation is that the niche of native and invasive populations should be similar ("niche conservatism"), namely they should occupy similar sub-spaces within a multidimensional space of environmental variables (Blonder et al., 2014; Carvalho and Cardoso, 2018; Hutchinson, 1957). Conversely, if the environmental conditions of an area fall outside of the environmental space defined by the species native range, the outcome of the introduction events is expected to be failure. However, this picture is complicated by the range of suitable environments that are available to the species in its native region - which may not express the full suite of suitable conditions - and by rapid evolutionary changes that can occur during an invasion (Blossey and Notzold, 1995). Both situations may lead to a shift in the niche of invading population toward the colonisation of novel environmental conditions (Broennimann et al., 2007, 2012; Petitpierre et al., 2012; Tingley et al., 2014; Torres et al., 2018).

The Chinese mitten crab Eriocheir sinensis (H. Milne Edwards, 1853) (Crustacea, Decapoda, Varunidae) has a native distribution stretching from China to Korea and is a commercially important aquaculture species, especially in China (Cheng et al., 2018; Dittel and Epifanio, 2009). Eriocheir sinensis is a catadromous species that lives in freshwater during its growth phase and migrates to the sea during its reproductive season (Cheng et al., 2018; Dittel and Epifanio, 2009). According to the China Fishery Statistical Yearbook (2017), aquaculture production of $E$. sinensis in China reached $>812,000 \mathrm{t}$ in 2016 . Outside its native range, E. sinensis is considered an invasive species that has successfully established breeding populations in Europe and North America (Brockerhoff and McLay, 2011; Dittel and Epifanio, 2009; Herborg et al., 2003). Previous studies have demonstrated the negative impacts of this invasive species in introduced regions, including predation on native species (Mills et al., 2016; Rosewarne et al., 2016; Rudnick and Resh, 2005; Webster et al., 2015; Wójcik et al., 2015), competition with native organisms (Gilbey et al., 2008; Zhang et al., 2019b), pathogen transmission (Schrimpf et al., 2014), and riverbank erosion (Dittel and Epifanio, 2009). Multiple introduction vectors are blamed for the transportation of E. sinensis into new habitats, including ballast water discharge, the live crab trade, and religious animal release practices (Cohen and Carlton, 1997; Dittel and Epifanio, 2009; Low et al., 2013).

Eriocheir sinensis has been designated as a potentially invasive species in Japan according to the Japanese Invasive Alien Species Act (Ministry of the Environment, Government of Japan, 2004). Given the frequent shipping activities and the geographical proximity of China and Japan, it is quite possible that E. sinensis larvae could be transported into Japanese coastal waters through ballast water. In addition, because E. sinensis is regarded as a food delicacy in Japan, live import is permitted (Fig. 1a). In 2018, $>103$ t of live E. sinensis with a commercial value of approximately 385 million JPY were imported to Japan (Fig. 1b). Around the year 2000, driven by commercial interest, local villagers in Chiba and Yamagata Prefectures even cultured this invasive species by releasing juveniles into paddy fields (Kobayashi, 2012; Takeda and Koizumi, 2005). Kobayashi (2012) assessed the invasion risk of E. sinensis in Japan using a habitat comparison approach proposed by Hanson and Sytsma (2008), and concluded that only the Ariake Sea was likely to provide suitable marine environments for the larval stages of this invasive species. However, despite the existence of multiple introduction vectors and possible suitable marine environments, only two adult female specimens of $E$. sinensis (one live and one dead) were found in November 2004 in Tokyo Bay, Japan (Takeda and Koizumi, 2005). This represents the only report of E. sinensis in natural habitats in Japan. It remains unclear why E. sinensis has not established any population in Japan to date.

Here, we sought to understand the extent to which the failed invasion of $E$. sinensis in Japan is due to lack of suitable habitat, and whether there is evidence of a niche shift in the populations of this species that have been successful in invading other regions. We reconstructed the niches of native and invading populations using geometrical $n$ dimensional hypervolumes (Blonder et al., 2014) and developed species distribution models (SDMs) to predict habitat suitability in native and invaded areas. SDM is an approach well suited to invasion biology (Peterson and Vieglais, 2001), and several SDM predictions have already been developed for E. sinensis (e.g., Capinha and Anastácio, 2011; Capinha et al., 2011; Herborg et al., 2007a, 2007b; Zhang et al., 2019a). Despite the fact that SDM is based on the assumption of niche conservatism and niche shift during biological invasions would pose great challenges in predicting invasive potential, previous studies highlight the usefulness and necessity of prioritizing invasion hotspots using niche conservatism (e.g. Broennimann and Guisan, 2008; Ørsted and Ørsted, 2019; Torres et al., 2018). In this study, we (1) tested whether a niche shift between the native and invasive ranges of $E$. sinensis in freshwater habitats had occurred, (2) developed three different SDMs for this species (i.e., native, invasive, and worldwide) and projected its habitat suitability to the Japanese freshwater environment, especially around the Ariake Sea, and (3) discussed the possible reasons for its failure to date to establish in Japan and evaluated its future invasion risk.

\section{Materials and methods}

\subsection{Species distribution data}

Because of the lack of information about the distribution of $E$. sinensis larvae in marine environments, we focused on freshwater habitats as reported by Zhang et al. (2019a). We retrieved worldwide records of the occurrence of $E$. sinensis from the published literature (Zhang 

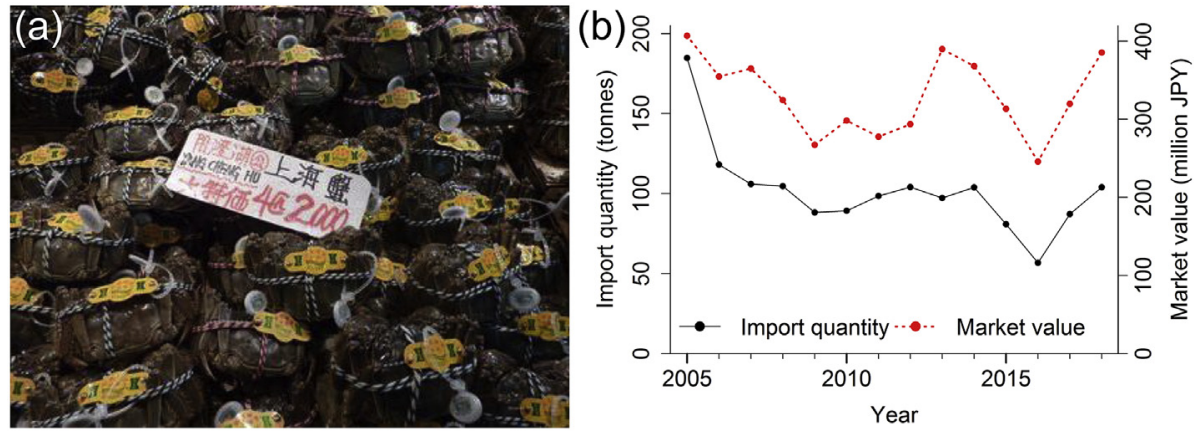

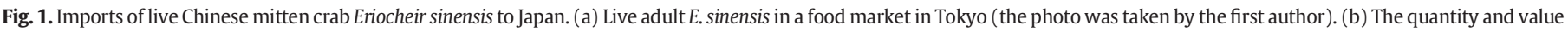

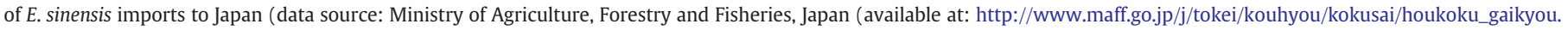
html\#r26).

et al., 2019a) and from several online repositories, including the DASSH archive for marine species and habitats data (https://www.dassh.ac.uk), the Global Biodiversity Information Facility (GBIF.org, 2020), the National Biodiversity Network Atlas (https://nbnatlas.org), the Nonindigenous Aquatic Species database of the US Geological Survey (https://nas. er.usgs.gov), and the United States Geological Survey's Biodiversity Information Serving Our Nation (https://bison.usgs.gov). To thin distribution data in heavily sampled regions, we retained only one occurrence record per 5-arcminute grid cell (Capinha and Anastácio, 2011; Capinha et al., 2011). This data cleaning process resulted in a thinned dataset with 70 native records and 580 invasive records (Supporting Information Fig. S1).

\subsection{Predictor variables}

Nineteen global land surface predictors at a spatial resolution of 30 arcsec were downloaded from the CHELSA database (http://chelsaclimate.org), which contains averaged bioclimatic variables for the period 1979-2013 (Karger et al., 2017) (Supporting Information Table S1). Because of the catadromous lifestyle of E. sinensis, we further considered a predictor variable representing the distance to the coast (details in Zhang et al., 2019a). Before analyses, we checked for collinearity between these 20 predictors by calculating pairwise Pearson $r$ correlation coefficients (details in Supporting Information Fig. S2). For strongly correlated predictors (i.e., $|r|>0.70$ ), we used only one variable for model development (Dormann et al., 2013). Based on the results of the collinearity analysis, we considered seven predictors in our analyses: annual mean temperature (bio1), mean diurnal range (bio2), temperature annual range (bio7), annual precipitation (bio12), precipitation of driest month (bio14), precipitation seasonality (bio15), and distance to the coast (dcoast) (Supporting Information Fig. S2, Table S1).

\subsection{Niche estimation}

We quantified the realized niche of $E$. sinensis in its native and invasive ranges using $n$-dimensional hypervolumes (Blonder et al., 2014, 2018). Making a close analogy with the Hutchinsonian niche concept (Hutchinson, 1957), this approach relies on high-dimensional kernel density estimation to delineate the shape and volume of the niche hyperspace in $n$ dimensions (Blonder et al., 2014, 2018), where $n$ is the number of orthogonal axes representing environmental conditions exploited by a given species - or species traits (Blonder, 2019). We first generated a principal component analysis (PCA) of the seven predictors to introduce exclusively orthogonal axes in the hypervolume estimation - note that the predictors were resampled to a resolution of 5 arcmin to reduce computation time. We retained the first four PCA axes (PCs) to delineate the shape of the niche, as these cumulatively explained almost $90 \%$ of the variance in the dataset. We used the hypervolume R package (Blonder, 2018) to generate hypervolumes, using Gaussian kernel density estimation and default settings for bandwidth estimation (Blonder et al., 2018). We generated a first hypervolume for describing the realized niche of the native population, and three separate hypervolumes for the three populations occurring in the main invaded areas (Europe, western US, and eastern US; Dittel and Epifanio, 2009).

To evaluate whether there had been a niche shift during invasions, we explored the overlap between native and invasive hypervolumes using both a distance (distance between hypervolume centroids) and a similarity metric ( $\beta$ diversity) (Mammola, 2019). We estimated centroid distance as the Euclidean distance between hypervolume centroids, using the hypervolume_distance $\mathrm{R}$ function (Blonder, 2018). We estimated $\beta$ diversity through the kernel.beta function in BAT R package (Mammola and Cardoso, 2020). This approach decomposes the two process underlying overall differentiation among hypervolumes $\left(\beta_{\text {total }}\right)$ : the replacement of space between hypervolumes ( $\left.\beta_{\text {replacement }}\right)$, reflecting niche shifts, and the net differences between the amount of space enclosed by each hypervolume $\left(\beta_{\text {richness }}\right)$, reflecting niche expansion or contraction (Carvalho and Cardoso, 2018). $\beta_{\text {total }}$ ranges from 0 (identical niches) to 1 (fully dissimilar niches), and $\beta_{\text {total }}=\beta_{\text {replacement }}+\beta_{\text {richness }}$.

\subsection{SDM development}

According to the different extents of the study areas (Supporting Information Fig. S1), we constructed three SDMs: (a) a native SDM using native distribution data, (b) an invasive SDM using invasive distribution records, and (c) a worldwide SDM using all native and invasive occurrence records. To overcome uncertainties resulting from single SDM algorithms, an ensemble modelling approach was used (Araújo and New, 2007; Guisan et al., 2017; Thuiller et al., 2019b). In brief, we used a consensus of 10 SDM algorithms, fitted with their default parameter settings in the biomod2 $\mathrm{R}$ package (Thuiller et al., 2019a). Species absence data is also essential for SDM development; since true absence data is often difficult to acquire, we used pseudoabsences as an alternative (Guisan et al., 2017; Thuiller et al., 2019b). Both the number and the way that pseudoabsences are selected play important roles in SDM studies (e.g. Barbet-Massin et al., 2012; Chapman et al., 2019). Herborg et al. (2007a) reported that the highest documented dispersal distance of $E$. sinensis was $1260 \mathrm{~km}$; therefore, for each SDM, we created buffer area with a radius of $1260 \mathrm{~km}$ from presence records and randomly selected 10,000 pseudoabsences within the corresponding buffer area. We evaluated the predictive abilities of 10 SDM algorithms through a fivefold cross-validation approach (Franklin, 2009; Guisan et al., 2017). In this approach, $80 \%$ of the data were randomly selected and used for model training and the remaining $20 \%$ for model testing. We repeated this procedure 10 times for each SDM algorithm. We measured the predictive accuracy of each algorithm via two evaluation metrics: the area under the receiver-operating characteristic curve (AUC; ranging from 0 to 1 , Swets, 1988) and the true skill statistics (TSS; 
ranging from -1 to 1 , Allouche et al., 2006). We only selected algorithms with AUC $>0.90$ and TSS $>0.75$ for all three SDMs for subsequent analyses (Allouche et al., 2006; Swets, 1988). We developed TSSweighted mean ensemble models for each SDM by using the selected algorithms. We evaluated predictive abilities of ensemble models using TSS, AUC, and the Boyce index (Table 1) (Boyce et al., 2002; Hirzel et al., 2006). The Boyce index ranges from -1 to +1 (negative values indicate counter prediction, values close to zero indicate model no better than random, and good model falls within positive values range). It is considered to be the most appropriate index to evaluate presenceonly predictions (Boyce et al., 2002; Guisan et al., 2017; Hirzel et al., 2006).

We transformed continuous habitat suitability maps into binary maps using a 10th percentile presence threshold (Pearson et al., 2007). The coefficient of variation (i.e. standard deviation/mean*100\%) across single SDM predictions was also calculated to measure uncertainty of the spatial maps.

\section{Results}

\subsection{Realized niches in native and invasive ranges}

The first four axes of the PCA of the seven selected predictors accounted for $90 \%$ of the total variance of the dataset, while variance contributed by other axes was relatively low (each axis <7\%) (Supporting Information Table S2, Figs. S3-S6). The volume of Eriocheir sinensis 4-dimensional hypervolume in its native range was 25.61, and virtually as voluminous as the western US populations hypervolume (25.16). Conversely, hypervolumes constructed for the eastern US and European populations were one order of magnitude less voluminous than the native hypervolume, respectively 6.20 and 1.23 (Fig. 2). We found that there was a low niche overlap between native and invasive populations, as emphasized both by the pairwise $\beta_{\text {total }}$ values close to 1 and by the distance among niche centroids (Table 2). The difference between native and invasive western US hypervolumes was almost exclusively attributable to niche shift ( $\beta_{\text {replacement }}$ ) (Table 2$)$, with invasive populations having shifted their niche especially with respect to PC1, 3 , and 4 (Fig. 2). On the contrary, $\beta_{\text {richness }}$ mostly explained differences in the range of conditions experienced by native and both the eastern US and European populations (Table 2). In particular, non-native populations in these areas are occupying a subset of the native niche, indicating niche contraction. Some niche shift was also observed in respect to PC2, particularly in eastern US populations (Fig. 2).

\subsection{SDM}

Model validation revealed that three algorithms (i.e. GBM, GLM, and Maxent) had good predictive ability for native, invasive, and worldwide SDMs (Fig. 3). The three ensemble SDMs built using the selected algorithms had excellent predictive abilities with TSS $>0.80$, AUC $>0.93$, and Boyce $>0.61$ (Table 1). The relative contribution of predictors varied between the three SDMs (Supporting Information Fig. S7). The three SDMs provided very different projections of habitat suitability for $E$. sinensis (Fig. 4). Generally, coefficient of variation values were smaller within suitable ranges than that within unsuitable ranges (Supporting Information, Figs. S8-S9). The native SDM provided reliable predictions of $E$. sinensis distribution in Asia, but this model failed to identify the distribution in Europe and North America (Fig. 4a, b, c). Similarly, the invasive SDM successfully predicted the distribution of E. sinensis in Europe and North America, but failed to predict its distribution pattern in the

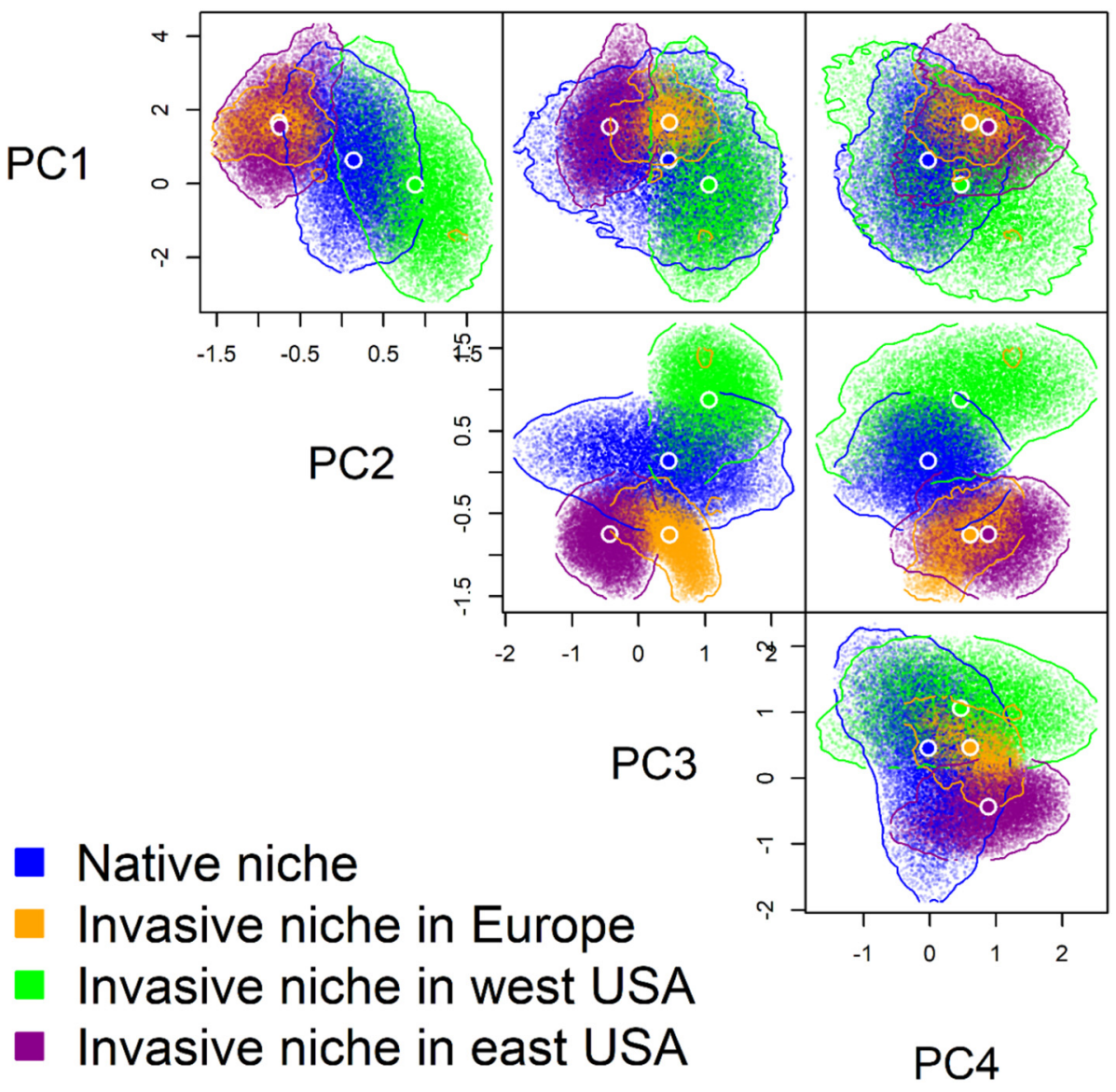

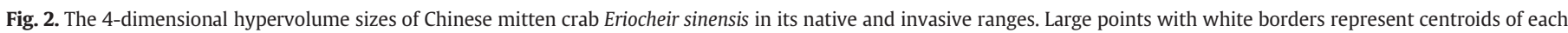
hypervolume. 10,000 random points were sampled from each hypervolume to delineate its shape and boundary. 
native range (Fig. 4d, e, f). The worldwide SDM provided good predictions for both native and invasive distribution patterns (Fig. $4 \mathrm{~g}, \mathrm{~h}, \mathrm{i}$ ).

Given the superiority of worldwide SDM in delineating the distribution of $E$. sinensis in both native and invasive ranges, we only presented habitat suitability of this species in Japan projected by worldwide SDM. The worldwide SDM predicted that a large part of the Japanese coastal area would be suitable for E. sinensis (Fig. 5a, b). The worldwide SDM also suggested that no suitable freshwater habitat exists along the coast of the Ariake Sea (Fig. 5). Interestingly, the native SDM and invasive SDM also indicated that there is no suitable freshwater habitat for E. sinensis near the Ariake Sea (Supporting Information Fig. S11).

To answer the question of why there is no suitable freshwater environments around the Ariake Sea, we extracted environmental values from presence records of $E$. sinensis in both its native and invaded range. We also created a $100 \mathrm{~km}$ radius buffer zone around the Ariake Sea and extracted environmental data within this buffer area (Supporting Information Fig. S12). We observed that around the Ariake Sea, all predictors except annual precipitation more or less overlap with those either from native range or from invasive ranges (Supporting Information Fig. S12). The annual precipitation values around the Ariake are significantly higher than those from where E. sinensis occur (Mann-Whitney $U$ Test, $p<3.1 \times 10^{-15}$; Supporting Information Fig. S12).

\section{Discussion}

For a comprehensive understanding of invasion ecology, it is important to study both successful and failed invasions (Allen and Ramcharan, 2001; Marchetti et al., 2004; Zenni and Nuñez, 2013). In the present study, we investigated a possible ecological explanations for the failure
Table 1

Predictive performances of three ensemble species distribution models (SDMs) and 10th percentile presence thresholds for three ensemble SDMs. Results of TSS, AUC, and Boyce are expressed as mean \pm standard error.

\begin{tabular}{lllll}
\hline SDMs & TSS $^{\mathrm{a}}$ & AUC $^{\mathrm{b}}$ & Boyce & Threshold \\
\hline Native & $0.805( \pm 0.012)$ & $0.938( \pm 0.004)$ & $0.619( \pm 0.063)$ & 0.608 \\
Invasive & $0.882( \pm 0.007)$ & $0.980( \pm 0.002)$ & $0.925( \pm 0.015)$ & 0.580 \\
Worldwide & $0.849( \pm 0.009)$ & $0.975( \pm 0.002)$ & $0.935( \pm 0.012)$ & 0.406 \\
\hline
\end{tabular}

a TSS: true skill statistics.

b AUC: area under the receiver-operating characteristic curve.

of $E$. sinensis in becoming established in Japan to date. Our results suggest that the potential mismatch between suitable freshwater and marine environments in Japan may be partially responsible for this phenomenon.

\subsection{Niche shifts in biological invasions}

The results of the $n$-dimensional hypervolume analysis suggested that a bioclimatic niche shift had occurred during the invasion process of $E$. sinensis in western US populations and only partly in eastern US and European ones. This was not an unexpected result, because niche shifts during biological invasions have been previously demonstrated for a variety of invasive species from terrestrial, freshwater, and marine habitats (e.g., Broennimann et al., 2007; Li et al., 2014; Parravicini et al., 2015; Petitpierre et al., 2012; Tingley et al., 2014; Torres et al., 2018). The niche shift in western US population leads this population to occupy a niche space of comparable size to that of native populations, although within a different range of environmental conditions. The $n$ -
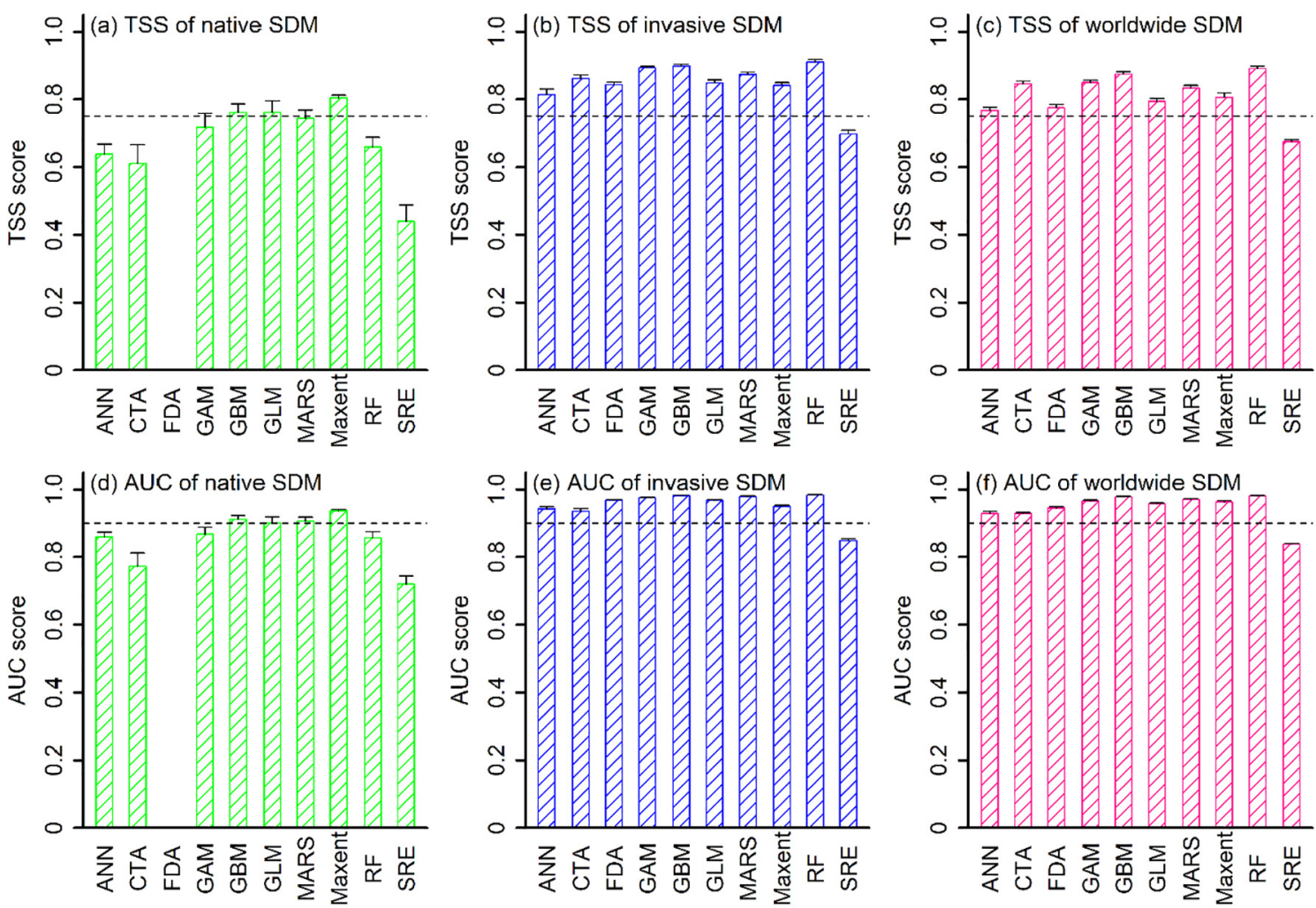

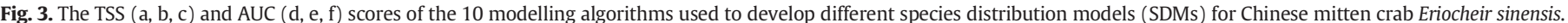

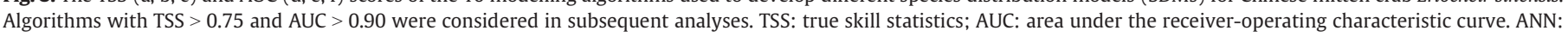

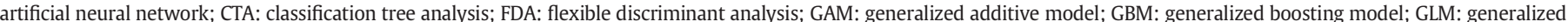

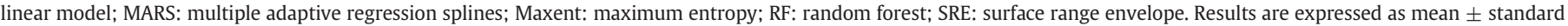

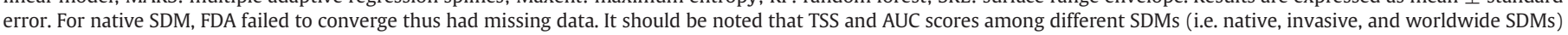
cannot be compared since these SDMs were developed using different presence-background datasets. 

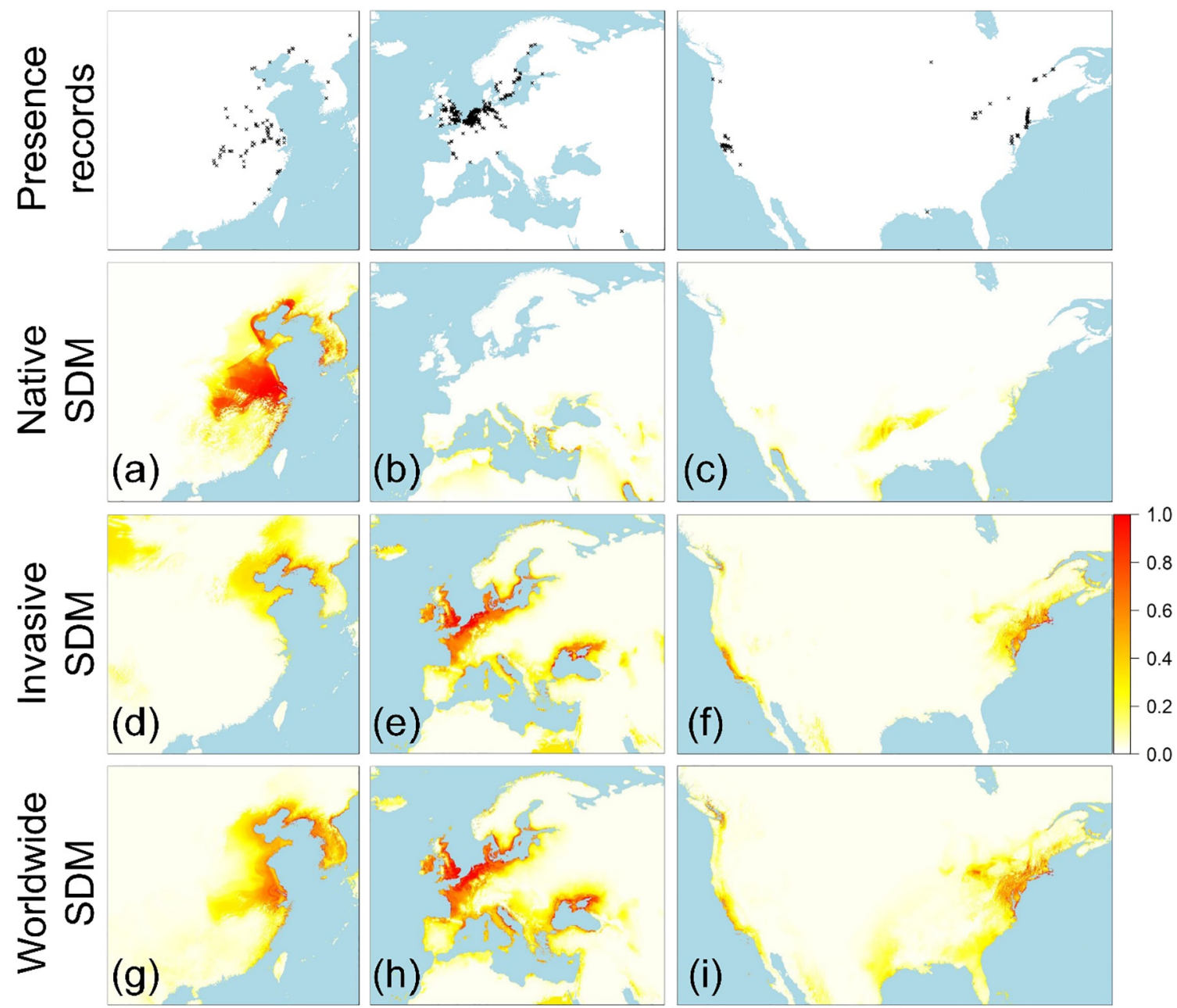

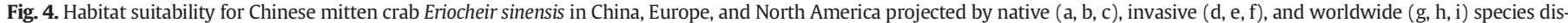
tribution models (SDMs). Projected habitat suitability varies from 0 (white) to 1 (red). Binary SDM predictions can be found in Supporting Information Fig. S10.

dimensional hypervolume calculated for the native populations was significantly more voluminous than the $n$-dimensional hypervolume for the invasive populations in Europe and eastern US. Since limited niche shifts were detected, this result suggest that invasive populations in Europe and eastern US underwent niche contraction, thus they occur in habitats characterized by a smaller set of bioclimatic conditions than those experienced by native populations. The lack of a greater niche shift or expansion in the invaded areas in Europe and eastern US may be due to competitive exclusion by native organisms, or simply because these invasions are recent.

Our three SDM projections provide further independent evidence for a niche shift between the native and invasive ranges of $E$. sinensis. The native and invasive SDMs were only helpful within the areas in which the SDMs were trained, and had low transferability for new areas. This low transferability probably resulted from the niche shift; whereas the worldwide SDM, which was developed using all distribution data, provided good predictions of distribution range in both native and invasive ranges. Our results provide further evidence in support of previous findings that when predicting habitat suitability for invasive species, pooling distribution data from entire ranges can provide reliable predictions and thus is recommended (e.g. Beaumont et al., 2009; Broennimann and Guisan, 2008; Jiménez-Valverde et al., 2011; Capinha et al., 2011). Our findings concerning the niche shift support those of a recent study by Torres et al. (2018), who quantified native and invasive niches for 22 invasive freshwater invertebrates, including E. sinensis, based on the framework proposed by Broennimann et al. (2012). One of the key assumptions when projecting habitat suitability for invasive species via SDMs is niche conservatism during biological invasions (Broennimann et al., 2007; Parravicini et al., 2015). As a result, niche shifts pose a great challenge to projections of habitat suitability

Table 2

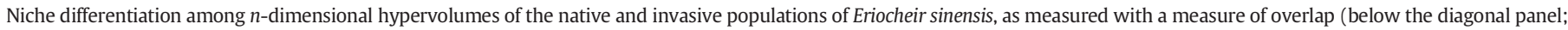
$\beta_{\text {total }}=\beta_{\text {replacement }}+\beta_{\text {richness }}$ ) and of distance (above the diagonal; distance between centroids).

\begin{tabular}{|c|c|c|c|c|}
\hline & Native & Europe & Eastern US & Western US \\
\hline Native & - & 1.51 & 1.79 & 1.25 \\
\hline Europe & $0.99=0.06+0.93$ & - & 0.95 & 2.42 \\
\hline Eastern US & $0.98=0.36+0.62$ & $0.93=0.24+0.69$ & - & 2.73 \\
\hline Eastern US & $0.84=0.83+0.01$ & $1.00=0.09+0.91$ & $1.00=0.39+0.61$ & - \\
\hline
\end{tabular}




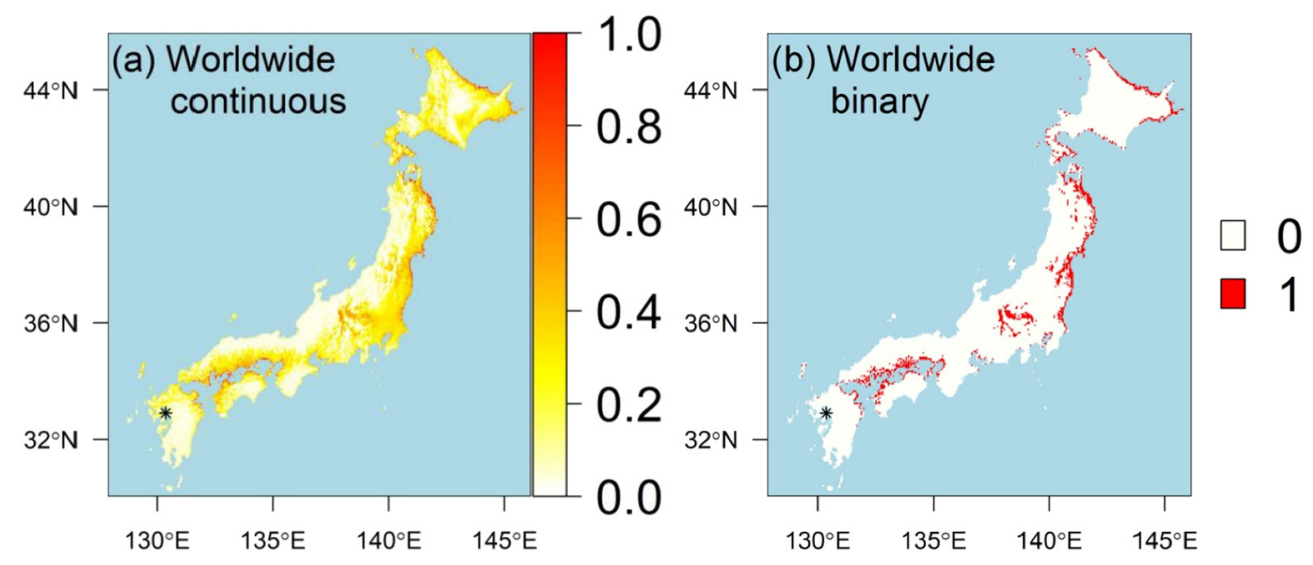

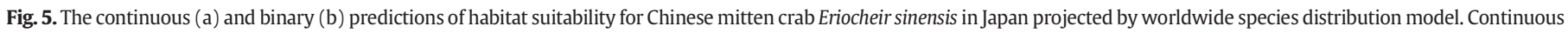
map was converted into binary map by using 10 th percentile presence threshold. The star symbols indicate the location of the Ariake Sea.

for invasive species solely based on native distribution data since native presences may not fully describe species environmental requirements.

\subsection{Possible explanations for the failed establishment of E. sinensis}

All three of our SDMs suggested that there is suitable freshwater habitat for this invasive species in Japan, although the sizes and locations of the predicted suitable habitat varied (Fig. 5, Supporting Information Fig. S11). Eriocheir sinensis is a catadromous species that requires freshwater habitats for growth and marine environments for reproduction (Cheng et al., 2018; Dittel and Epifanio, 2009). Therefore, both freshwater habitats and marine environments are important for this species. We previously developed a periodic stage-based matrix population model for $E$. sinensis using published information about its life history (Zhang et al., 2019c). Our results highlighted the important role of the larval stage in regulating the population dynamics of $E$. sinensis, and consequently, the significant role of marine environments where pelagic larvae live. Unfortunately, thus far, information about the distribution of E. sinensis larvae is scarce, which hinders our ability to develop a SDM to estimate the habitat suitability for E. sinensis larvae in marine environments. Kobayashi (2012) highlighted that marine environments in the Ariake sea are likely to be suitable for E. sinensis larvae. Interestingly, all three SDMs suggested that there is no suitable freshwater habitat for E. sinensis around the Ariake Sea area (Fig. 5, Supporting Information Fig. S11). Our results indicate that suitable freshwater and marine habitats for this species in Japan are not connected, which may partially account for the failure to date of $E$. sinensis to establish in Japan.

High level of annual precipitation in freshwater habitats around the Ariake Sea region may adversely affect $E$. sinensis through different mechanisms, such as reducing dissolved oxygen (Tundisi and Tundisi, 2012). For instance, Tundisi and Tundisi (2012, page 122) explicitly mentioned that "...the level of dissolved oxygen drops drastically when the levels of suspended matter markedly increase after heavy precipitation and drainage into lakes, ponds or rivers". Previous study demonstrated that low levels of dissolved oxygen have adverse effects on immune ability, physiological response, and hepatopancreatic metabolism of juvenile E. sinensis (Qiu et al., 2011). Further studies are required to investigate the potential impacts of heavy precipitation on E. sinensis. It should be noted that larvae of E. sinensis mainly occur in spring (Dittel and Epifanio, 2009); during this time period, both river discharge and precipitation in Ariake Bay are small (Yanagi and Abe, 2005), which ensure the suitability of Ariake Sea for larval survival and settlement of $E$. sinensis (Hanson and Sytsma, 2008; Kobayashi, 2012).

In addition to the above-mentioned abiotic resistance mechanism, biotic resistance may also play some role in the failed establishment of $E$. sinensis in Japan. The Japanese mitten crab E. japonica is a widely distributed native of Japan (Zhang et al., 2019b). We previously investigated shelter competition between male pairs of invasive E. sinensis and native E. japonica under laboratory conditions (Zhang et al., 2019b). Our results clearly showed that native $E$. japonica are competitively superior to sizematched invasive $E$. sinensis and display more frequent aggressive behavior. Hence, it is reasonable to hypothesize that the existence of a widely distributed strong native competitor might also contribute to the failure of establishment of invasive E. sinensis in Japan.

\subsection{Further perspectives}

Based on these and previous results, it is not possible to conclude with absolute certainty that $E$. sinensis invasion of Japan is not a concern, and we therefore encourage further studies. To estimate more accurately the habitat suitability of marine habitats, distribution data for $E$. sinensis larvae should be collected and a SDM for marine habitats should be developed. Furthermore, E. sinensis could negatively interact with native Japanese species via different pathways. Schrimpf et al. (2014) confirmed that this species can serve as a vector for the crayfish plague pathogen Aphanomyces astaci, which could pose a threat to native Japanese freshwater species. For instance, Martín-Torrijos et al. (2018) reported that the pathogen $A$. astaci caused two mass mortality events in the endangered Japanese native crayfish Cambaroides japonicus. In addition, invasive $E$. sinensis and native E. japonica have the same numbers of chromosomes ( $2 \mathrm{n}=146)$ (Lee et al., 2004); therefore, it is possible that the two species could hybridize and produce viable offspring. In fact, Vladivostok (Russia) is considered a sympatric zone for $E$. sinensis and E. japonica, and hybridization between the two species in this region has been confirmed by molecular techniques (e.g., Kang et al., 2018; Xu et al., 2009; Xu and Chu, 2012). Further studies are required to verify whether invasive $E$. sinensis can hybridize with pure $E$. japonica from the Japanese archipelago. Another possible scenario is that invasive E. sinensis may consume native Japanese freshwater species and negatively affect their population dynamics. Our preliminary experiments showed that both male and female adult E. sinensis can prey intensively on native juvenile $E$. japonica under laboratory conditions (Supporting Information Fig. S13). Eriocheir japonica is a cannibalistic species, and habitat segregation among different-sized individuals along river courses is suggested to be an evolutionary adaptation to avoid cannibalism (Zhang et al., 2018). In freshwater habitats predicted to be suitable for $E$. sinensis, this invasive species may heavily consume small natives and adversely influence the recruitment and stability of $E$. japonica populations. Future work is needed to test this hypothesis.

\subsection{Management strategies}

Given the potential risks, we propose several management strategies for preventing invasive E. sinensis in Japan. Our SDM predictions highlight 
that a large part of Japanese coastal regions may provide suitable freshwater environments for E. sinensis. These regions deserve more attention and should be prioritized in monitoring the presence of the species. Existing introduction vectors should be managed cautiously to mitigate the potential introduction of this invasive species into Japan. For instance, ballast water should be treated properly before being released, especially in the Ariake sea. Several ballast water treatment methods, both physical (e.g., heat, ultraviolet light, and deoxygenation) and chemical (e.g., ozone, hydrogen peroxide, and chlorine dioxide), have been proposed to kill marine organisms transported via ballast water (Tsolaki and Diamadopoulos, 2010; Zhan et al., 2015). Meanwhile, live trade in E. sinensis should be carefully managed. The Japanese government has recently implemented strict regulations for the live trade of E. sinensis. For example, E. sinensis can only be purchased live by customers with special permission; otherwise, live crabs must be frozen before sale. Despite of these regulations, it is still relatively easy to buy live E. sinensis from these markets (Zhang, personal observation). Thus, further management strategies should be considered. In addition to preventing possible introduction vectors, monitoring programs to detect the early stages of invasion of Japan by E. sinensis should be considered. Environmental DNA (eDNA) is capable of detecting invasive species at low densities; this enables the rapid implementation of eradication programs, thereby increasing the success of eradication efforts (Ficetola et al., 2008; Zhan et al., 2015). Recently, Robinson et al. (2019) used the eDNA technique to study the spatial distribution of E. sinensis within three rivers in Great Britain. We encourage researchers to develop species-specific eDNA markers for E. sinensis and E. japonica and consider the use of eDNA for the early detection of E. sinensis in Japan.

\section{CRediT authorship contribution statement}

Zhixin Zhang: Conceptualization, Data curation, Formal analysis; Methodology, Software, Validation, Visualization, Writing - original draft, Writing - review \& editing. Stefano Mammola: Conceptualization, Formal analysis, Methodology, Software, Validation, Visualization, Writing - original draft, Writing - review \& editing. Colin L. McLay: Conceptualization, Validation, Visualization, Writing - original draft, Writing review \& editing. César Capinha: Validation, Visualization, Writing - review \& editing. Masashi Yokota: Conceptualization, Funding acquisition, Investigation, Project administration, Resources, Supervision, Validation, Visualization, Writing - review \& editing.

\section{Declaration of competing interest}

None.

\section{Acknowledgements}

We thank Drs Huijie Qian (Institute of Zoology, Chinese Academy of Sciences, China), Xuan Liu (Institute of Zoology, Chinese Academy of Sciences, China), and Chenghui Wang (Shanghai Ocean University, China) for their helpful suggestions on an early draft of this manuscript. We also thank three anonymous reviewers for constructive suggestions.

\section{Funding}

This work was financially supported by the Japan Society for the Promotion of Science Grant-in-Aid for Scientific Research (C) 18K05780 to MY. This work was supported by national funds from FCT - Portuguese Foundation for Science and Technology UIDB/00295/2020.

\section{Data availability}

Occurrence records of $E$. sinensis are available from the published literature (Zhang et al., 2019a) and online repositories, including DASSH (https://www.dassh.ac.uk), the Global Biodiversity Information Facility (http://www.gbif.org), the National Biodiversity Network Atlas (https://nbnatlas.org), the Nonindigenous Aquatic Species database of the US Geological Survey (https://nas.er.usgs.gov), and the United States Geological Survey's Biodiversity Information Serving Our Nation (https://bison.usgs.gov). The assembled occurrence database is also available from the first author upon request.

\section{Appendix A. Supplementary data}

Supplementary data to this article can be found online at https://doi. org/10.1016/j.scitotenv.2020.138815.

\section{References}

Allen, Y.C., Ramcharan, C.W., 2001. Dreissena distribution in commercial waterways of the US: using failed invasions to identify limiting factors. Can. J. Fish. Aquat. Sci. 58, 898-907. https://doi.org/10.1139/cjfas-58-5-898.

Allouche, O., Tsoar, A., Kadmon, R., 2006. Assessing the accuracy of species distribution models: prevalence, kappa and the true skill statistic (TSS). J. Appl. Ecol. 43, 1223-1232. https://doi.org/10.1111/j.1365-2664.2006.01214.x.

Araújo, M.B., New, M., 2007. Ensemble forecasting of species distributions. Trends Ecol. Evol. 22, 42-47. https://doi.org/10.1016/j.tree.2006.09.010.

Barbet-Massin, M., Jiguet, F., Albert, C.H., Thuiller, W., 2012. Selecting pseudo-absences for species distribution models: how, where and how many? Methods Ecol. Evol. 3, 327-338. https://doi.org/10.1111/j.2041-210X.2011.00172.x.

Beaumont, L.J., Gallagher, R.V., Thuiller, W., Downey, P.O., Leishman, M.R., Hughes, L., 2009. Different climatic envelopes among invasive populations may lead to underestimations of current and future biological invasions. Divers. Distrib. 15, 409-420. https://doi.org/10.1111/j.1472-4642.2008.00547.x.

Bellard, C., Cassey, P., Blackburn, T.M., 2016. Alien species as a driver of recent extinctions Biol. Lett. 12, 20150623. https://doi.org/10.1098/rsbl.2015.0623.

Blonder, B., with contributions from Harris, D. J, 2018. Hypervolume: high dimensional geometry and set operations using Kernel density estimation, support vector machines, and convex hulls. R package version 2.0.11. https://CRAN.R-project.org/package $=$ hypervolume.

Blonder, B., 2019. Hypervolume concepts in niche- and trait-based ecology. Ecography 41, 1441-1455. https://doi.org/10.1111/ecog.03187.

Blonder, B., Lamanna, C., Violle, C., Enquist, B.J., 2014. The n-dimensional hypervolume Glob. Ecol. Biogeogr. 23, 595-609. https://doi.org/10.1111/geb.12146.

Blonder, B., Morrow, C.B., Maitner, B., Harris, D.J., Lamanna, C., Violle, C., Enquist, B.J., Kerkhoff, A.J., 2018. New approaches for delineating $n$-dimensional hypervolumes. Methods Ecol. Evol. 9, 305-319. https://doi.org/10.1111/2041-210X.12865.

Blossey, B., Notzold, R., 1995. Evolution of increased competitive ability in invasive nonindigenous plants: a hypothesis. J. Ecol. 83, 887-889. https://doi.org/10.2307/2261425

Boyce, M.S., Vernier, P.R., Nielsen, S.E., Schmiegelow, F.K., 2002. Evaluating resource selection functions. Ecol. Model. 157, 281-300. https://doi.org/10.1016/S0304-3800(02) 00200-4.

Brockerhoff, A., McLay, C.L., 2011. Human-mediated spread of alien crabs. In: Galil, B.S. Clark, P.F., Carlton, J.T. (Eds.), In the Wrong Place-Alien Marine Crustaceans: Distribution, Biology and Impacts. Invading Nature Springer Series in Invasion Ecology. Springer, Dordrecht, pp. 27-106.

Broennimann, O., Guisan, A., 2008. Predicting current and future biological invasions: both native and invaded ranges matter. Biol. Lett. 4, 585-589. https://doi.org/ 10.1098/rsbl.2008.0254.

Broennimann, O., Treier, U.A., Müller-Schärer, H., Thuiller, W., Peterson, A.T., Guisan, A., 2007. Evidence of climatic niche shift during biological invasion. Ecol. Lett. 10, 701-709.

Broennimann, O., Fitzpatrick, M.C., Pearman, P.B., Petitpierre, B., Pellissier, L., Yoccoz, N.G., Thuiller, W., Fortin, M., Randin, C., Zimmermann, N.E., Graham, C.H., Guisan, A., 2012. Measuring ecological niche overlap from occurrence and spatial environmental data. Glob. Ecol. Biogeogr. 21, 481-497. https://doi.org/10.1111/j.1466-8238.2011.00698.x.

Capinha, C., Anastácio, P., 2011. Assessing the environmental requirements of invaders using ensembles of distribution models. Divers. Distrib. 17, 13-24. https://doi.org/ 10.1111/j.1472-4642.2010.00727.x.

Capinha, C., Leung, B., Anastácio, P., 2011. Predicting worldwide invasiveness for four major problematic decapods: an evaluation of using different calibration sets. Ecography 34, 448-459. https://doi.org/10.1111/j.1600-0587.2010.06369.x.

Carvalho, J.C., Cardoso, P., 2018. Decomposing the causes for niche differentiation between species using hypervolumes. BioRxiv, 485920 https://doi.org/10.1101/485920.

Chapman, D. Pescott, O.L, Roy, H.E., Tanner, R., 2019. Improving species distribution models for invasive non-native species with biologically informed pseudo-absence selection. J. Biogeogr. 46, 1029-1040. https://doi.org/10.1111/jbi.13555.

Cheng, Y., Wu, X., Li, J., 2018. Chinese Mitten Crab Culture: Current Status and Recent Progress Towards Sustainable Development. Aquaculture in China: Success Stories and Modern Trends. , pp. 197-217. https://doi.org/10.1002/9781119120759.ch3_2.

China Fishery Statistical Yearbook, 2017. Ministry of Agriculture. China Agriculture Press, Beijing.

Cohen, A.N., Carlton, J.T., 1997. Transoceanic transport mechanisms: introduction of the Chinese mitten crab, Eriocheir sinensis, to California. Pac. Sci. 51, 1-11.

Dittel, A.I., Epifanio, C.E., 2009. Invasion biology of the Chinese mitten crab Eriocheir sinensis: a brief review. J. Exp. Mar. Biol. Ecol. 374, 79-92. https://doi.org/10.1016/j. jembe.2009.04.012. 
Dormann, C.F., Elith, J., Bacher, S., Buchmann, C., Carl, G., Carré, G., Marquéz, J.R.G., Gruber, B., Lafourcade, B., Leitão, P.J., Münkemüller, T., McClean, C., Osborne, P.E., Reineking, B., Schröder, B., Skidmore, A.K., Zurell, D., Lautenbach, S., 2013. Collinearity: a review of methods to deal with it and a simulation study evaluating their performance. Ecography 36, 27-46. https://doi.org/10.1111/j.1600-0587.2012.07348.x.

Ehrenfeld, J.G., 2010. Ecosystem consequences of biological invasions. Annu. Rev. Ecol. Evol. Syst. 41, 59-80. https://doi.org/10.1146/annurev-ecolsys-102209-144650.

Ficetola, G.F., Miaud, C., Pompanon, F., Taberlet, P., 2008. Species detection using environmental DNA from water samples. Biol. Lett. 4, 423-425. https://doi.org/10.1098/ rsbl.2008.0118.

Franklin, J., 2009. Mapping Species Distributions: Spatial Inference and Prediction. Cambridge University Press, Cambridge.

GBIF.org, 28 February 2020. GBIF Occurrence Download. https://doi.org/10.15468/ dl.6vftmg.

Genovesi, P., 2005. Eradications of invasive alien species in Europe: a review. Biol. Invasions 7, 127-133. https://doi.org/10.1007/s10530-004-9642-9.

Giakoumi, S., Katsanevakis, S., Albano, P.G., Azzurro, E., Cardoso, A.C., Cebrian, E., ... Mačić V., 2019. Management priorities for marine invasive species. Science of the Total Environment 688, 976-982. https://doi.org/10.1016/j.scitotenv.2019.06.282.

Gilbey, V., Attrill, M.J., Coleman, R.A., 2008. Juvenile Chinese mitten crabs (Eriocheir sinensis) in the Thames estuary: distribution, movement and possible interactions with the native crab Carcinus maenas. Biol. Invasions 10, 67-77. https://doi.org/ 10.1007/s10530-007-9110-4.

Guisan, A., Thuiller, W., Zimmermann, N.E., 2017. Habitat Suitability and Distribution Models: With Applications in R. Cambridge University Press, Cambridge.

Hänfling, B., Edwards, F., Gherardi, F., 2011. Invasive alien Crustacea: dispersal, establish ment, impact and control. BioControl 56, 573-595. https://doi.org/10.1007/s10526011-9380-8.

Hanson, E., Sytsma, M., 2008. The potential for mitten crab Eriocheir sinensis H. Milne Edwards, 1853 (Crustacea: Brachyura) invasion of Pacific Northwest and Alaskan estuaries. Biol. Invasions 10, 603-614. https://doi.org/10.1007/s10530-007-9156-3.

Herborg, L.M., Rushton, S.P., Clare, A.S., Bentley, M.G., 2003. Spread of the Chinese mitten crab (Eriocheir sinensis H. Milne Edwards) in Continental Europe: analysis of a historical data set. Hydrobiologia 503, 21-28. https://doi.org/10.1023/B:HYDR.0000008483.63314.3c.

Herborg, L.M., Jerde, C.L., Lodge, D.M., Ruiz, G.M., MacIsaac, H.J., 2007a. Predicting invasion risk using measures of introduction effort and environmental niche models. Ecol. Appl. 17, 663-674. https://doi.org/10.1890/06-0239.

Herborg, L.M., Rudnick, D.A., Siliang, Y., Lodge, D.M., MacIsaac, H.J., 2007b. Predicting the range of Chinese mitten crabs in Europe. Conserv. Biol. 21, 1316-1323. https://doi org/10.1111/j.1523-1739.2007.00778x.

Hirzel, A.H., Le Lay, G., Helfer, V., Randin, C., Guisan, A., 2006. Evaluating the ability of habitat suitability models to predict species presences. Ecol. Model. 199, 142-152. https://doi.org/10.1016/j.ecolmodel.2006.05.017.

Hutchinson, G.E., 1957. Concluding remarks. Cold Spring Harb. Symp. Quant. Biol. 22 415-427. https://doi.org/10.1101/SQB.1957.022.01.039

Ings, T.C., Ings, N.L., Chittka, L., Rasmont, P., 2010. A failed invasion? Commercially introduced pollinators in Southern France. Apidologie 41, 1-13. https://doi.org/10.1051/ apido/2009044.

Jeschke, J.M., Heger, T., 2018. Invasion Biology: Hypotheses and Evidence. CABI, Wallingford, UK.

Jiménez-Valverde, A., Peterson, A.T., Soberón, J., Overton, J.M., Aragón, P., Lobo, J.M., 2011. Use of niche models in invasive species risk assessments. Biol. Invasions 13 2785-2797. https://doi.org/10.1007/s10530-011-9963-4.

Kang, W., Huang, S., Chen, X., Wang, J., Ohtomi, J., Wang, C., 2018. Genetic admixture of mitten crabs in the Northeast Asia hybrid zones. Hydrobiologia 806, 203-214. https://doi.org/10.1007/s10750-017-3358-1.

Karger, D.N., Conrad, O., Böhner, J., Kawohl, T., Kreft, H., Soria-Auza, R.W., Zimmermann, N.E., Linder, H.P., Kessler, M., 2017. Climatologies at high resolution for the earth's land surface areas. Sci. Data 4, 170122. https://doi.org/10.1038/sdata.2017.122.

Kobayashi, S., 2012. Invasive biology of the mitten crab Eriocheir spp. (3) possibility of invasion of Eriocheir sinensis into Japan and interaction with native species. Seibutsu Kagaku 63, 175-189 (in Japanese).

Lee, T.H., Naitoh, N., Yamazaki, F., 2004. Chromosome studies on the mitten crabs Eriocheir japonica and E. sinensis. Fish. Sci. 70, 211-214. https://doi.org/10.1111/j.14442906.2003.00793.x

Li, Y., Liu, X., Li, X., Petitpierre, B., Guisan, A., 2014. Residence time, expansion toward the equator in the invaded range and native range size matter to climatic niche shifts in nonnative species. Glob. Ecol. Biogeogr. 23, 1094-1104. https://doi.org/10.1111/geb.12191.

Lockwood, J.L., Hoopes, M.F., Marchetti, M.P., 2013. Invasion Ecology. 2nd edn. John Wiley \& Sons, West Sussex

Low, B.W., Ng, N.K. Yeo, D.C., 2013. First record of the invasive Chinese mitten crab, Eriocheir sinensis H. Milne Edwards, 1853 (Crustacea: Brachyura: Varunidae) from Singapore. BioInvasions Rec. 2, 73-78. https://doi.org/10.3391/bir.2013.2.1.13.

Mammola, S., 2019. Assessing similarity of $n$-dimensional hypervolumes: which metric to use? J. Biogeogr. 0, 1-12. https://doi.org/10.1111/jbi.13618.

Mammola, S., Cardoso, P., 2020. Functional diversity metrics using kernel density ndimensional hypervolumes. bioRxiv https://doi.org/10.1101/2020.01.25.919373.

Marchetti, M.P., Moyle, P.B., Levine, R., 2004. Alien fishes in California watersheds: charac teristics of successful and failed invaders. Ecol. Appl. 14, 587-596. https://doi.org/ 10.1890/02-5301.

Martín-Torrijos, L., Kawai, T., Makkonen, J., Jussila, J., Kokko, H., Diéguez-Uribeondo, J. 2018. Crayfish plague in Japan: a real threat to the endemic Cambaroides japonicus. PLoS One 13, e0195353. https://doi.org/10.1371/journal.pone.0195353.

Mehta, S.V., Haight, R.G., Homans, F.R., Polasky, S., Venette, R.C., 2007. Optimal detection and control strategies for invasive species management. Ecol. Econ. 61, 237-245. https://doi.org/10.1016/j.ecolecon.2006.10.024.
Mills, C.D., Clark, P.F., Morritt, D., 2016. Flexible prey handling, preference and a novel capture technique in invasive, sub-adult Chinese mitten crabs. Hydrobiologia 773, 135-147. https://doi.org/10.1007/s10750-016-2700-3.

Ministry of the Environment, Government of Japan, 2004. The Invasive Alien Species Act (Law No. 78 (June 2, 2004)). available at. www.env.go.jp/en/nature/as.html.

Morri, C., Montefalcone, M., Gatti, G., Vassallo, P., Paoli, C., Bianchi, C.N., 2019. An alien invader is the cause of homogenization in the recipient ecosystem: a simulation-like approach. Diversity 11, 146. https://doi.org/10.3390/d11090146.

Ørsted, I.V., Ørsted, M., 2019. Species distribution models of the Spotted Wing Drosophila (Drosophila suzukii, Diptera: Drosophilidae) in its native and invasive range reveal an ecological niche shift. J. Appl. Ecol. 56, 423-435. https://doi.org/10.1111/1365-2664.13285.

Parravicini, V., Azzurro, E., Kulbicki, M., Belmaker, J., 2015. Niche shift can impair the ability to predict invasion risk in the marine realm: an illustration using Mediterranean fish invaders. Ecol. Lett. 18, 246-253. https://doi.org/10.1111/ele.12401.

Pearson, R.G., Raxworthy, C.J., Nakamura, M., Townsend Peterson, A., 2007. Predicting species distributions from small numbers of occurrence records: a test case using cryptic geckos in Madagascar. J. Biogeogr. 34, 102-117. https://doi.org/10.1111/ j.1365-2699.2006.01594.x

Peterson, A.T., Vieglais, D.A., 2001. Predicting species invasions using ecological niche modeling: new approaches from bioinformatics attack a pressing problem. BioScience 51 , 363-371. https://doi.org/10.1641/0006-3568(2001)051[0363:PSIUEN]2.0.CO;2.

Petitpierre, B., Kueffer, C., Broennimann, O., Randin, C., Daehler, C., Guisan, A., 2012. Climatic niche shifts are rare among terrestrial plant invaders. Science 335, 1344-1348. https://doi.org/10.1126/science.1215933.

Pimentel, D., Zuniga, R., Morrison, D., 2005. Update on the environmental and economic costs associated with alien-invasive species in the United States. Ecol. Econ. 52, 273-288. https://doi.org/10.1016/j.ecolecon.2004.10.002.

Qiu, R., Cheng, Y., Huang, X., Wu, X., Yang, X., Tong, R., 2011. Effect of hypoxia on immunological, physiological response, and hepatopancreatic metabolism of juvenile Chinese mitten crab Eriocheir sinensis. Aquac. Int. 19, 283-299. https://doi.org/10.1007/ s10499-010-9390-z.

Robinson, C.V., de Leaniz, C.G., Consuegra, S., 2019. Effect of artificial barriers on the distribution of the invasive signal crayfish and Chinese mitten crab. Sci. Rep. 9, 7230. https://doi.org/10.1038/s41598-019-43570-3.

Rosewarne, P.J., Mortimer, R.J., Newton, R.J., Grocock, C., Wing, C.D., Dunn, A.M., 2016. Feeding behaviour, predatory functional responses and trophic interactions of the invasive Chinese mitten crab (Eriocheir sinensis) and signal crayfish (Pacifastacus leniusculus). Freshw. Biol. 61, 426-443. https://doi.org/10.1111/fwb.12717.

Rudnick, D., Resh, V., 2005. Stable isotopes, mesocosms and gut content analysis demonstrate trophic differences in two invasive decapod crustacea. Freshw. Biol. 50, 1323-1336. https://doi.org/10.1111/j.1365-2427.2005.01398.x.

Schrimpf, A., Schmidt, T., Schulz, R., 2014. Invasive Chinese mitten crab (Eriocheir sinensis) transmits crayfish plague pathogen (Aphanomyces astaci). Aquat. Invasions 9, 203-209. https://doi.org/10.3391/ai.2014.9.2.09.

Simberloff, D., Martin, J.L., Genovesi, P., Maris, V., Wardle, D.A., Aronson, J., Courchamp, F., Galil, B., García-Berthou, E., Pascal, M., Pyšek, P., Sousa, R., Tabacchi, E., Vilà, M., 2013. Impacts of biological invasions: what's what and the way forward. Trends Ecol. Evol. 28, 58-66. https://doi.org/10.1016/j.tree.2012.07.013.

Swets, J.A., 1988. Measuring the accuracy of diagnostic systems. Science 240, 1285-1293. https://doi.org/10.1126/science.3287615.

Takeda, M., Koizumi, M., 2005. Occurrence of the Chinese mitten crab, Eriocheir sinensis H. Milne Edwards, in Tokyo Bay, Japan. Bulletin of the National Science Museum. Series A. Zoology 31, 21-24.

Thuiller, W., Georges, D., Engler, R., Breiner, F., 2019a. biomod2: ensemble platform for species distribution modeling. R package version 3.3-7.1. https://CRAN.R-project. org/package $=$ biomod2

Thuiller, W., Guéguen, M., Renaud, J., Karger, D.N., Zimmermann, N.E., 2019b. Uncertainty in ensembles of global biodiversity scenarios. Nat. Commun. 10, 1446. https://doi.org/ 10.1038/s41467-019-09519-w.

Tingley, R., Vallinoto, M., Sequeira, F., Kearney, M.R., 2014. Realized niche shift during a global biological invasion. Proc. Natl. Acad. Sci. 111, 10233-10238. https://doi.org/ 10.1073/pnas.1405766111.

Torres, U., Godsoe, W., Buckley, H.L., Parry, M., Lustig, A., Worner, S.P., 2018. Using niche conservatism information to prioritize hotspots of invasion by non-native freshwater invertebrates in New Zealand. Divers. Distrib. 24, 1802-1815. https://doi.org/ 10.1111/ddi.12818.

Tsolaki, E., Diamadopoulos, E., 2010. Technologies for ballast water treatment: a review. J. Chem. Technol. Biotechnol. 85, 19-32. https://doi.org/10.1002/jctb.2276.

Tundisi, J.G., Tundisi, T.M., 2012. Limnology. CRC Press, Balkema, Leiden, The Netherlands. Webster, J., Clark, P., Morritt, D., 2015. Laboratory based feeding behaviour of the Chinese mitten crab, Eriocheir sinensis (Crustacea: Decapoda: Brachyura: Varunidae): fish egg consumption (De Haan, 1835). Aquat. Invasions 10, 313-326. https://doi.org/ 10.3391/ai.2015.10.3.06.

Wójcik, D., Normant, M., Dmochowska, B., Fowler, A., 2015. Impact of Chinese mitten crab Eriocheir sinensis on blue mussel Mytilus edulis trossulus-laboratory studies of claw strength, handling behavior, consumption rate, and size selective predation. Oceanologia 57, 263-270. https://doi.org/10.1016/j.oceano.2015.03.003.

Xu, J., Chu, K.H., 2012. Genome scan of the mitten crab Eriocheir sensu stricto in East Asia: population differentiation, hybridization and adaptive speciation. Mol. Phylogenet. Evol. 64, 118-129. https://doi.org/10.1016/j.ympev.2012.03.009.

Xu, J., Chan, T.Y., Tsang, L.M., Chu, K.H., 2009. Phylogeography of the mitten crab Eriocheir sensu stricto in East Asia: Pleistocene isolation, population expansion and secondary contact. Mol. Phylogenet. Evol. 52, 45-56. https://doi.org/10.1016/j.ympev.2009.02.007.

Yanagi, T., Abe, R., 2005. Increase in water exchange ratio due to a decrease in tidal amplitude in Ariake Bay, Japan. Cont. Shelf Res. 25, 2174-2181. https://doi.org/10.1016/j. csr.2005.08.019. 
Zenni, R.D., Nuñez, M.A., 2013. The elephant in the room: the role of failed invasions in understanding invasion biology. Oikos 122, 801-815. https://doi.org/10.1111/ j.1600-0706.2012.00254.x.

Zhan, A., Briski, E., Bock, D.G., Ghabooli, S., Maclsaac, H.J., 2015. Ascidians as models for studying invasion success. Mar. Biol. 162, 2449-2470. https://doi.org/10.1007/ s00227-015-2734-5.

Zhang, Z., Yokota, M., Strüssmann, C.A., 2018. Cannibalism in the Japanese mitten crab, Eriocheir japonica. Hydrobiologia 807 (1), 367-376. https://doi.org/10.1007/s10750017-3411-0.

Zhang, Z., Capinha, C., Weterings, R., McLay, C.L., Xi, D., Lü, H., Yu, L., 2019a. Ensemble forecasting of the global potential distribution of the invasive Chinese mitten crab,
Eriocheir sinensis. Hydrobiologia 826, 367-377. https://doi.org/10.1007/s10750-0183749-y.

Zhang, Z., Yokota, M., Strüssmann, C.A., 2019b. Potential competitive impacts of the invasive Chinese mitten crab Eriocheir sinensis on native Japanese mitten crab Eriocheir japonica. Hydrobiologia 826, 411-420. https://doi.org/10.1007/s10750-018-3759-9.

Zhang, Z., Yokota, M., Strüssmann, C.A., 2019c. A periodic matrix population model to predict growth potential of the invasive Chinese mitten crab Eriocheir sinensis (H. Milne Edwards, 1853)(Decapoda: Brachyura: Varunidae). J. Crustac. Biol. 39, 28-35. https:// doi.org/10.1093/jcbiol/ruy090. 